\title{
Comparative Analysis of Total Station Measuring Inclination and Settlement
}

\author{
Youliang Wang \\ College of Information Science and Engineering, Shandong Agricultural University, Taian, China
}

Email address:

wyL@sdau.edu.cn

To cite this article:

Youliang Wang. Comparative Analysis of Total Station Measuring Inclination and Settlement. American Journal of Civil Engineering. Vol. 7, No. 2, 2019, pp. 47-51. doi: 10.11648/j.ajce.20190702.12

Received: April 19, 2019; Accepted: May 20, 2019; Published: May 23, 2019

\begin{abstract}
Total station to measure the inclination of high-rise building is the important way to detect the perpendicularity of the building, the settlement measurement is an important means of building deformation analysis, the use of settlement measurement data can be indirectly calculated building oblique. This paper uses 2016.6-2018.07 high-rise building level observation data and total station tilt observation data. The article introduces the inclined deformation measured by total station instrument without prism, the inclined deformation calculated by level measuring settlement, and the inclined deformation calculated indirectly by plane regression method. Data analysis time three stages, the first stage, the construction of buildings to the overall level of half, the second stage, general building construction completed, the third stage, the overall building completed half a year, in the three stage, two methods of measuring calculation of slope deformation may be inconsistent, the article analyses the reasons for not consistent, the corresponding conclusion, through the periods of tilt calculation can obtain continuous tilting deformation law, two methods to confirm each other, make sure the safety of the whole construction process and the stability of the building. The applicability of plane regression tilting deformation is illustrated, and the practicability and reliability of total station measurement analysis method and plane regression analysis method in building tilting deformation analysis are illustrated with examples.
\end{abstract}

Keywords: Total Station, Inclination, Settlement Measurement, Plane Regression

\section{Introduction}

In the process of construction and operation of high-rise buildings, there are problems such as uneven load distribution caused by its own structure, uneven foundation, construction quality and special environmental conditions, etc., which will make high-rise buildings deform. Settlement deformation is particularly important in deformation observation. In practice, settlement deformation is simple and accurate, which can not only reflect the settlement amount, but also infer the inclination of high-rise buildings. In the life cycle of high-rise buildings from the start of construction, settlement has always existed. As a deformation, settlement is a normal phenomenon within a certain limit, but if it exceeds the whole limit, it will affect the safety of high-rise buildings. It may cause the cracking of the main structure of the building, and even lead to the serious consequences of building toppling $[1,2]$. The phenomenon of building settlement is caused by three reasons: the first one is that the vertical line is not vertical due to the error in the construction process; the second reason is the compression deformation of the foundation rock and soil in the use of the building, the normal settlement deformation and gradually stable. The third reason is abnormal, such as uneven foundation, groundwater, etc. In order to prevent the uneven settlement of the foundation from causing the cracking and damage of the building and ensure the normal use of the building, the deformation of the foundation, especially the uneven settlement, must be monitored and controlled [3], tradition of building deformation monitoring data processing, it is through comparing the periods measured results of settlement point, obtain the structure of the settlement and deformation, tilt in the aspect of data expression has been more mature methods and experience [4-6], Deformation prediction is also discussed [7]. In the high-rise building monitoring methods, mainly include, global positioning system (GPS) [8], measurement robot, photogrammetry $[9,10]$, tilt sensor method, total station [11], etc. $T$ This paper discusses the consistency between the calculated inclination of the foundation settlement of a typical high-rise building and the measured inclination of the total station. 


\section{Measurement Method and Implement}

\subsection{Project Summary}

The 11\# high-rise residential buildings are planned to be built in a community project, among which, buildings $1 \#$ to $8 \#$ are 11 floors above ground and 2 floors underground, and the houses are used as residential buildings. 9\# to $11 \#$ are 17 floors above ground, 2 floors underground, raft foundation, reinforced concrete shear wall structure. 11\# building is 17 floors above ground. The floor plan of the building is approximately rectangular, with a total length of $49.2 \mathrm{~m}$ in the east-west direction and a expansion joint in the middle. The total length in the south-north direction is $12.0 \mathrm{~m}$ and the total building height is $50.8 \mathrm{~m}$. The settlement observation points are arranged at the corner around the building, and the height in the middle of the building is 0.2 to $0.5 \mathrm{~m}$. The plane layout of the settlement observation points is shown in figure 1 , and $\mathrm{A} 1 \sim \mathrm{A} 8$ is named., settlement observation was carried out with 2 levelling methods.

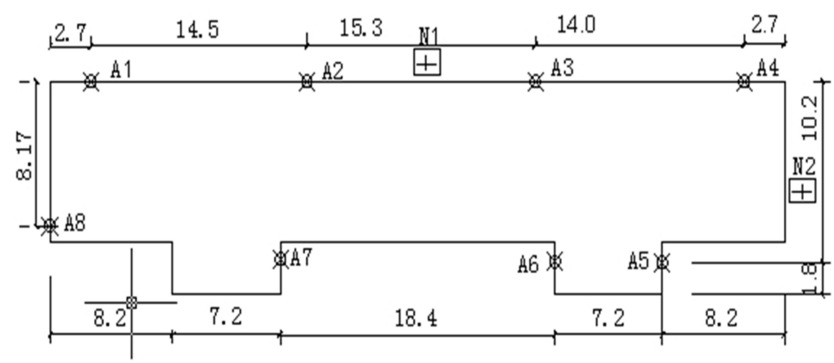

Figure 1. Position Arrangement of Inclined Observation Point and Settlement Observation Point.

\subsection{Total Station Tilt Observation}

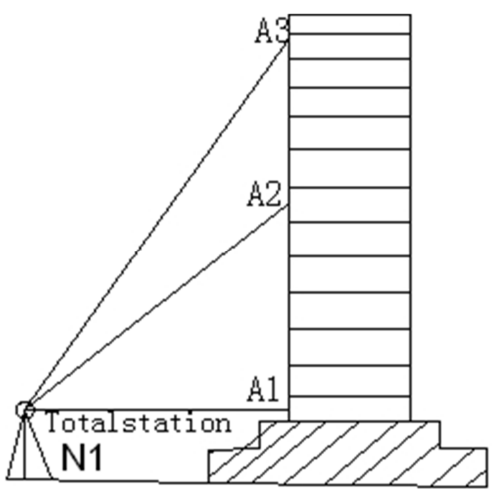

Figure 2. Schematic diagram of total station observation.

Building main body tilt observations using total station, $\mathrm{N} 1$ and N2 point in figure 1, total station, distance from total station building should be more than half of the height measurement point. Use prism free observation, survey points within the same vertical surface, the measurement of A1, A2, $\mathrm{A} 3$, take the coordinate difference and elevation difference between $\mathrm{A} 2$ and $\mathrm{A} 3$ points to $\mathrm{A} 1$ points, can be calculated in $\mathrm{N} 1$ point measurement of tilt, total station observations in latitudinal direction, but for the north-south direction tilt, in what each direction observation to find out things on direction of tilt. The tilt observation of this project has been carried out for 3 times. The first observation is from the floor construction to the 10th floor, and the north-south tilt is measured. The second observation was made on the 17 th floor, and the main body was completed. The third observation took place six months after the completion of the project. The principle of total station observation is shown in figure 2.

\section{Plane Regression Model}

The plane regression model takes the building as a whole as the research object. The settlement observation points are buried on the foundation or wall of a building, the actual position of the observation points may not be completely on the same plane,

The initial elevation of each point is set to be zero, the observation points are located on the same theoretical level [7].

The height (zi) of each point is obtained by observing the subsidence of each subsidence points.

Given that the plane coordinates of each point are (xi, yi), multivariate linear regression is conducted by using the sedimentation observation point, and the regression plane equation is:

$$
\hat{z}=a+b x+c y
$$

We can solve it by the least squares principle, a, b, c, The valuation of $\mathrm{Q}$, Make the error sum of squares.

$$
Q=\sum_{i=1}^{n}\left(z_{i}-\hat{z}_{i}\right)^{2}=\sum_{i=1}^{n}\left(z_{i}-a-b x_{i}-c y_{i}\right)
$$

To minimize:

$$
v_{i}=a+b x_{i}+c y_{i}-z_{i}
$$

$v_{i}$ the settlement difference between the observation point and the vertical direction of the regression plane. Formula (2) is expressed as matrix:

$$
\left.\left[\begin{array}{l}
v_{1} \\
v_{2} \\
\vdots \\
v_{n}
\end{array}\right]=\left[\begin{array}{ccc}
1 & x_{1} & y_{1} \\
1 & x_{2} & y_{2} \\
& \vdots & \\
1 & x_{n} & y_{n}
\end{array}\right]\left[\begin{array}{l}
a \\
b \\
c
\end{array}\right]-\left[\begin{array}{l}
z_{1} \\
z_{2} \\
\vdots \\
z_{n}
\end{array}\right]\right]
$$

(3) Is the error equation of the coefficient and constant terms of the regression plane equation based on $n$ sedimentation observation points, and:

$$
v=\left[\begin{array}{l}
v_{1} \\
v_{2} \\
\vdots \\
v_{n}
\end{array}\right] K=\left[\begin{array}{ccc}
1 & x_{1} & y_{1} \\
1 & x_{2} & y_{2} \\
\vdots & \\
1 & x_{n} & y_{n}
\end{array}\right] X=\left[\begin{array}{l}
a \\
b \\
c
\end{array}\right] L=\left[\begin{array}{l}
z_{1} \\
z_{2} \\
\vdots \\
z_{n}
\end{array}\right]
$$


There is an error equation for indirect adjustment: $V=K X-L$ According to the least square principle, the estimation of $\mathrm{a}, \mathrm{b}$ and $\mathrm{c}$ can be obtained.

Determine the inclined deformation state. The equation of the plane in equation (1) is changed into the following form: $A x+B y+C z+D=0$

$$
A=b, \quad B=c, \quad C=-1
$$

The inclined direction of the normal line of the regression plane can be determined by using the coefficients A, B and C of the regression plane. The included angles between the normal line and the $\mathrm{x}, \mathrm{y}$ and $\mathrm{z}$ axes are respectively, which reflect the overall tilting and deformation state of the building.

$$
\begin{aligned}
& \alpha=\arccos \left(A / \sqrt{A^{2}+B^{2}+C^{2}}\right) \\
& \beta=\arccos \left(B / \sqrt{A^{2}+B^{2}+C^{2}}\right) \\
& \gamma=\arccos \left(C / \sqrt{A^{2}+B^{2}+C^{2}}\right)
\end{aligned}
$$

\section{Examples and Analysis}

The main building of \# 11 building in the area will be observed once every 2 floors; After the completion of the main body, observation shall be made for 1 year, once every 2 months, 6 times in total, and 16 times in total. The

\begin{tabular}{|c|c|c|c|c|c|c|c|c|c|c|}
\hline Number & Time & A1 & A2 & A3 & A4 & A5 & A6 & A7 & A8 & Average \\
\hline 1 & 2016.06 .07 & 0 & 0 & 0 & 0 & 0 & 0 & 0 & 0 & 0.00 \\
\hline 2 & 2016.07 .04 & -1 & -2.4 & -3.31 & -1.82 & -2.91 & -2.45 & -2.05 & -1.77 & -2.21 \\
\hline 3 & 2016.08 .02 & -2.15 & -5.13 & -6.14 & -4.11 & -5.28 & -5.09 & -4.27 & -3.52 & -4.46 \\
\hline 4 & 2016.09 .23 & -3.05 & -7.24 & -8.28 & -6.44 & -6.8 & -7.17 & -6.03 & -5.92 & -6.37 \\
\hline 5 & 2016.10 .22 & -2.94 & -8.24 & -8.32 & -6.68 & -7.52 & -8.06 & -7.64 & -5.83 & -6.90 \\
\hline 6 & 2016.11 .24 & -3.89 & -7.43 & -8.66 & -7.36 & -7.13 & -7.14 & -6.37 & -5.5 & -6.69 \\
\hline 7 & 2016.12 .21 & -3.87 & -7.02 & -8.5 & -7.6 & -6.13 & -8.11 & -7.77 & -6.5 & -6.94 \\
\hline 8 & 2017.02 .20 & -4.37 & -7.49 & -8.9 & -8.7 & -6.54 & -8.56 & -7.92 & -6.91 & -7.42 \\
\hline 9 & 2017.04 .07 & -4.74 & -7.49 & -8.9 & -7.29 & -6.2 & -7.93 & -7.38 & -7.03 & -7.12 \\
\hline 10 & 2017.06 .18 & -4.94 & -10.12 & -8.9 & -7.62 & -7.84 & -8.33 & -6.24 & -6.91 & -7.61 \\
\hline 11 & 2017.08.20 & -7.74 & -11.96 & -12.27 & -10.14 & -10.5 & -10.94 & -9.22 & -9.31 & -10.26 \\
\hline 12 & 2017.10 .26 & -9.21 & -13.42 & -12.43 & -11.6 & -13.06 & -12.73 & -10.55 & -10.78 & -11.47 \\
\hline 13 & 2017.12 .16 & -11.29 & -15.33 & -14.21 & -13.05 & -15.01 & -14.56 & -12.34 & -11.76 & -13.19 \\
\hline 14 & 2018.03.29 & -12.53 & -16.84 & -16.24 & -15.31 & -17.65 & -17.24 & -14.61 & -13.98 & -15.55 \\
\hline 15 & 2018.05 .30 & -12.46 & -17.16 & -17.02 & -16.32 & -17.21 & -16.48 & -14.04 & -14.72 & -15.68 \\
\hline 16 & 2018.07 .19 & -12.77 & -17.68 & -17.01 & -16.86 & -18.09 & -17.74 & -14.74 & -14.26 & -16.14 \\
\hline
\end{tabular}
statistical table of the final deformation amount of the deformation point of building 11 is shown in table 1

Table 1. 11\# final deformation statistics for building deformation points.

The observation period of building 11 lasted from June 7, 2016 to July 19, 2018, with a total observation time of 24 months. The typical settlement variation curve is shown in figure 3. According to statistics, with the continuous increase of load, the accumulative settlement also increases, and the accumulative settlement of the main structure remains basically unchanged for a period of time after completion. For general observation engineering, according to the requirements of building deformation measurement regulations, if the settlement velocity is less than $0.01 \sim 0.04 \mathrm{~mm} / \mathrm{d}$ in the last 100 days, it can be considered to enter the stable stage. The total sedimentation of each point is shown in table 2 .

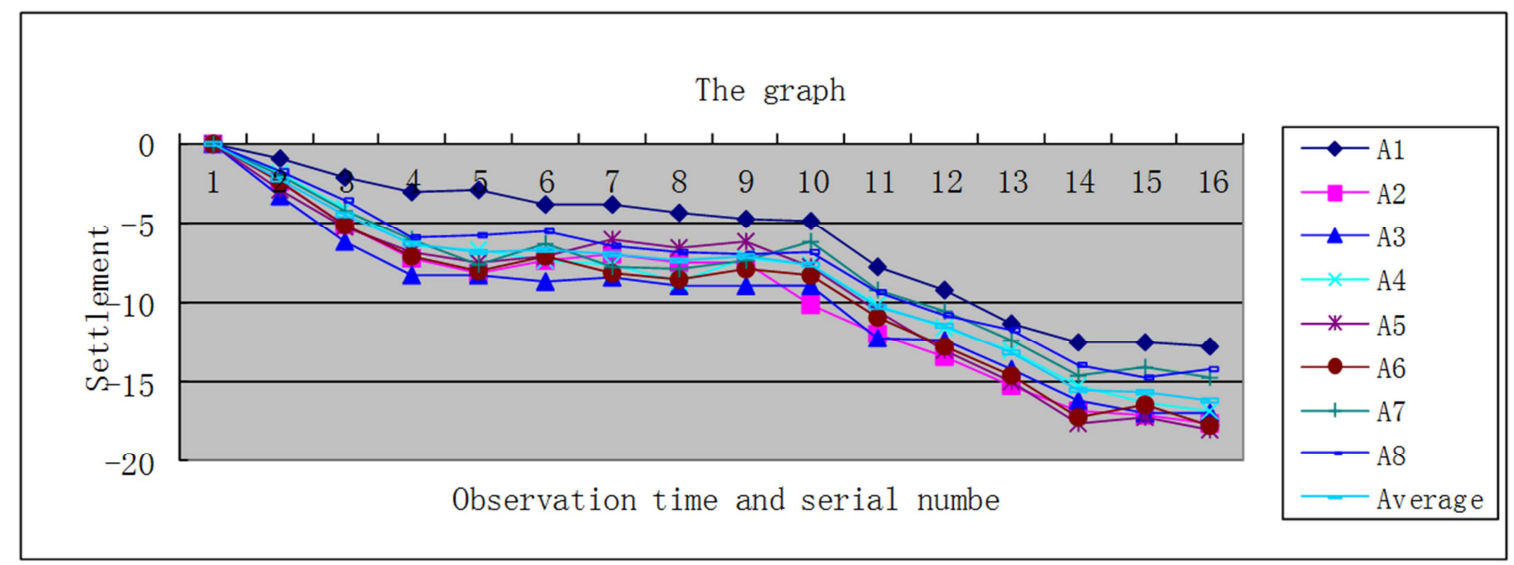

Figure 3. The settlement and deformation curves of each point of the 11 \# building. 
Table2. Total settlement scale of settlement observation points.

\begin{tabular}{lllllll}
\hline Point & X & Y & $\begin{array}{l}\text { Settlement }(\mathbf{m m}) \text { 10th } \\
\text { floor }\end{array}$ & Settlement 17th floor (I) & $\begin{array}{l}\text { Half a year after } \\
\text { completion (II) }\end{array}$ \\
\hline A1 & 10.2 & 2.7 & -2.94 & -4.94 & -12.77 \\
(II-I)
\end{tabular}

After the settlement observation is completed, the average settlement velocity is calculated to be $0.008 \mathrm{~mm} / \mathrm{d}$. The point with the largest settlement is A5, and its settlement is $18.09 \mathrm{~mm}$. The point with the smallest settlement is A1, and its settlement is $12.77 \mathrm{~mm}$. The differential settlement between the maximum and minimum points is $5.32 \mathrm{~mm}$, and the average total settlement is $16.14 \mathrm{~mm}$. This example is calculated by the final total settlement. The comparison table of regression plane and vertical alignment measurement is shown in table 3 .

Table 3. Comparison table of regression plane and vertical alignment measurement.

\begin{tabular}{|c|c|c|c|c|c|c|c|c|}
\hline Time & $\alpha$ & $\boldsymbol{\beta}$ & $\gamma$ & $\mathbf{X}$ & $\mathbf{Y}$ & tilt & X Consistency & Y Consistency \\
\hline 10th floor & $89^{\circ} 59^{\prime}$ & $90^{\circ} 01^{\prime}$ & $21^{\prime \prime}$ & 4.1 & 1.8 & $32^{\prime \prime}$ & $\sqrt{ }$ & $\times$ \\
\hline 17 th floor & $90^{\circ} 01^{\prime}$ & $90^{\circ} 01^{\prime}$ & $14^{\prime \prime}$ & 2.3 & -3.6 & $17^{\prime \prime}$ & $x$ & $\sqrt{ }$ \\
\hline Differential Settlement (B-A) & $89^{\circ} 59^{\prime}$ & $90^{\circ} 01^{\prime}$ & $20^{\prime \prime}$ & 2.8 & -4.7 & $11^{\prime \prime}$ & $\sqrt{ }$ & $\sqrt{ }$ \\
\hline
\end{tabular}

Table 3 shows the data consistency analysis. In table 3, equation of the second behavior and the 10th layer can be obtained by plane regression:

$$
0.8951 * 10^{-4} x-0.5835 * 10^{-4} y-z-0.0059897=0
$$

The surface normal direction and perpendicular to the $\mathrm{Z}$ axis Angle $0{ }^{\circ} 0 ' 21^{\prime \prime}$, with an Angle of $89^{\circ} 59^{\prime}$, the $X$ axis and $\mathrm{Y}$ axis Angle is $90^{\circ} 01^{\prime}$; Total station measuring deviation of layer 10, $\mathrm{X}$ direction $+4.1 \mathrm{~mm}$, Y direction $+1.8 \mathrm{~mm}$, and the $\mathrm{Z}$ axis Angle 32". The two methods of calculation are consistent in the $\mathrm{X}$ direction and inconsistent in the $\mathrm{Y}$ direction. The formulas for other rows and floors in table 2 are not listed. In table 2, some are consistent and some are not. There are several reasons for the inconsistency between dip observation and settlement observation. First, the building has no inclination. There is error in the measurement results. The slope calculated by the two methods is the surface phenomenon, and the actual floor is vertical. Second, the two methods reflect the sedimentation process is different. In the process of building, the generation of subsidence and the observation of subsidence by level are cumulative processes. The vertical collimator measurement is made in real time before the floor is sealed. If there is an error in the 10th floor of lofting, the deviation or settlement may be corrected in the 11th floor of lofting. The inclination measured by vertical collimator after capping should be consistent with the calculated results of settlement measurement.

In table 3 two kinds of method to calculate the tilt value is small, the largest tilt of $30^{\prime \prime}$. Body tilt code is less than 0.002 , or $0^{\circ} 06{ }^{\prime} 52^{\prime \prime}$ requirements. The analysis shows that the settlement of the whole building is relatively uniform, and it can be determined that the non-uniform settlement of the foundation produces less additional stress and the building is in a stable state.

\section{Conclusion}

In this paper, from the two aspects of settlement observation data processing and total station measurement and calculation of tilt, the paper discusses the vertical discrimination method of high-rise buildings in the construction process, analyzes the reasons for the inconsistency between the two methods, and draws the main conclusions as follows.1. Both methods can calculate the body tilt. The slope value calculated from the settlement measurement data should be within the same time period as the data used by the two methods of vertical alignment measurement; otherwise, they may not be consistent.2. The tilt result calculated from the settlement measurement data is smaller than that obtained from the total station measurement, which is inconsistent in the same period of time. It is caused by the measurement error, and the building body does not tilt.3. Two methods to calculate the tilt can effectively evaluate the safety of buildings. The two methods verify each other and ensure the safety of the whole construction process and the stability of the building. However, there is still a lack of case verification for large inclined buildings. In the further practical work, GPS method, image measurement method, dynamic monitoring method [12], etc. will be combined to make an in-depth comparative analysis of the inclined law of high-rise buildings. 


\section{References}

[1] ZHANG Xiqian. Super High-rise Building Construction Technology in the World's Leading Level in China [J]. Construction Technology, 2018, 47 (06): 5-12.).

[2] Li QM Research on incline-rectifying of building with pile foundation. Jordan J Civil Eng (2015) 9 (1): 133-138.

[3] NG C W W, WONG K S. Investigation of passive failure and deformation mechanisms due to tunnelling in clay $[\mathrm{J}]$. Canadian Geotechnical Journal, 2013, 50 (4): 359-372.

[4] WANG Tianying, XU Yaming. Research Dynamic Characteristic Monitoring Methods for Super High-rise Building [J]. Bulletin of Surveying and Mapping, 2017 (04): 89-92.

[5] Shahnazari H, Shahin MA. Tutunchian MA (2014) Evolutionary based approaches for settlement prediction of shallow foundations on cohesionless soils. Int Civil Eng 12 (1): $55-64$.

[6] Meenwah Gui, Shongloong Chen. Estimation of transverse ground surface settlement induced by DOT shield tunneling [J]. Tunnelling and Underground Space Technology incorporating Trenchless Technol- ogy Research, 2013, 33.

[7] WANG You-Liang, TANG Yue-Gang, LI Zenjian. Distortion forecast for inverse multivariate statistical model [J]. Science of Surveying and Mapping, 2009, 34 (06): 135-137.).

[8] WANG Yong, LIN Cairong, GUO Jiming, YIN Chaofan, ZHANG Di. Point Monitoring Analysis of Super High Rise Building Based on BDS+GPS Technology [J]. Bulletin of Surveying and Mapping, 2017 (06): 5-8.).

[9] ZHANG Guojian, YU Chengxin, GUO Guangli. Application of Digital Close-range Photogrammetry in the Deformation Observation of Check Gate [J]. Journal of Shandong University (Engineering Scence), 2017, 47 (06): 46-51.

[10] XIAO Weizhi, YAMG Wei, WANG Tianying. The measurement robot of daily swing monitoring of super high-rise building [J]. Science of Surveying and Mapping, 2018, 43 (08): 76-79.

[11] TONG Pengcheng, ZHANG Tongbo. BIM Technology Combined with Measurement Robot Lofting Function in the Field of High-rise Buildings. [J]. Bulletin of Surveying and Mapping, 2018 (11): 161-163.

[12] FENG Xiaomin, LIU Shangguo, YU Shengwen. Discussion on the 3D Coordinates Combined Measurement Method in Linear Space [J]. Science of Surveying and Mapping, 2015, 40 (08): 77-81. 